\title{
Research and Protection of the National Traditional Music near Gansu with the background of"Silk Road Economic Zone"
}

—_Lotus Hill flowers in Kangle County Based on the theory of oral

\section{programming}

\author{
Jing Yuanyuan \\ Lanzhou City University,College of Music,Gansu,Lanzhou 730070, China
}

Keywords: National Traditional Music, ilk Road Economic Zone,oral programming

Abstract. "Flowers" is an oral folk song in Qinghai, Gansu, Mingxia and other provinces, their lyrics wereinspired by the daily life, the Flowers reflect the local culture and national historyin flexible rhyme. This paper will focus on the national culture of "Flowers" on the "Silk Road's economic belt". This paper combed thegeneral situation ofLotus Hill "flowers", and detailed the characteristics of the "Flowers". The author started from the structureof Flower and analyzedits national culture. Finally, from the present situation and problems of the Flowers, author has put forward the corresponding countermeasures.

\section{Introduction}

"Flowers" is a kind of folk song which popular in Qinghai, Gansu, Mingxia and other provinces. According to the cradle of "flowers", it can be divided into three categories: "the Hezhou flowers", "Taomin flowers" and "Xining flower".

In the Taomin region, namely Lintan, Minxian, Weiyuan, Lintao and Kangle areas, the Louts Hill Flowers are quite popular in the locals. Flowers are widely spread and have a lot of singers in these areas. Whether the Han, Hui or Tibetan, many of them can sing impromptu. In Gansu, there has the largest rally of Flowers in every years' lunar June. Singers will have parties in Louts Hill on the 1stand 2th days of the June; on 3th and 4th they will hike in the mountains and sing to each other; on the 5th day they will light a bonfire and sing through the night at Wangjia Dich; at last, they will hold a farewell in Zisong Mountain. During this period, people will hike and sing freely, sometime the numbers of people can reach 10thousands. Louts Hill Flowers have many processes like "intercept the road with Malian ropes”, "sing across the mountains”, “a long farewell”. People are watching under their umbrellas, siting freely and singing impromptu. Some places will hold a high stage for singers to compete, the winners will wear red ribbons as a reward. The Flowers rally is a carnival of song and poetry.

Usually singers sing The Louts Hill Flowers with small groups of 3 to 5 members, one is responsible for the composition, the others singing in turns. Their songs usually ends with the words like "the flowers" and "the louts" in every 3 or more sentences. The amazing speed, and strict rhythm become the unique characteristics of Lotus Flowers. The composer was also called "Leader of Flowers", they are the souls of Flowers who are experienced in work and sing. Only after they have been familiar with the rhythms and lyrics, singers can compose impromptu. The "Flowers Rally" has a widely base in the locals. The performance of Flowers Rally is the competition 
between teams, each team has least 3 members lead by their "Leader of Flowers" the composition should be based on the questions asked by the other team. Then one singer tellslyrics to next singer and sing by the last singer. With the progress of economy and the penetration of modern civilization, the best environment of Flowers was broken gradually. TheLiving space of traditional "Flowers Rally” was reduced rapidly, the singers' number is decreasing which make it is hard to inherit the culture. The current backbone of the inheritance of flowers were those 40 to 75 years old in Taomin areas. Most of the young generations in 80s and 90s have accepted the education, they wereinfluencedby the new things and pop songs. So, only rarely people who stick to the "Flowers". In addition, the speeding up of the population flow and popularizeof electronic media and penetrate ofpop music, they are all the factors that have influenced the spreadof the Louts Hill Flowers.

\section{The characteristics of the Louts Hill Flowers}

The structure of the lyrics. A "Flower", no matter how many sentences, which has only one rhymecalled "the single set of Flowers". Each of it has three sentences, each sentences of seven words, more for 4 pauses, rhyme. During the Flower Rally, sentences can be increased to four, five and even six sentences by the singer's will. On the formal structure, lotus flowers belong to a body that only has one paragraph. It was constituted of some specific sentences likereappear sentences, repeat sentences and the sentences for dominant. When necessary, reappearance and repeating sentences can be repeated many times, as long as theystick to rhyme, it does not have much impact on singing, it still belong to the single set of Flowers. The "double set of Flowers" usually meansFlowers that have two rhymes, the rhymes are 1351 and 246 in four or six sentences. The "three-time transfer tone" is a Flower with three rhymes, the 1st and 2th sentence make up a rhyme, 2thand 4th sentences make up a rhyme, 5th and 6th sentences make up a rhyme, usually has 6 sentences. From the perspective of creation, "three-time transfer tone" has the longest length, which can express colorful emotions, due to rhymes, is very difficult to work.

To sum up the "three-time transfer tone" is most difficult then is the double-sets rhyme, one-set rhyme is easy to create, so it has taken the most part of Flowers creation.Thus it is easy to find that phrases, rhythms and lyrics of the Lotus Flower were rigorous in stipulation. The flexibility of Louts Hill Flowers is mainly embodied in the phrases' numbers and the broadness of rhyme. Because of the particularity of the local language, some singers have cut the13 to 11 quotes, there was no difference in the level tone and rising tone.

Content format. Most Louts Hill Flowers can be divided into three categories: love songs, songs of life and the ritual songs. With the development of the society, the Flowers which praise the communist party of Chinaand the policies called "policy Flowers". Below each category, the Flowers can be divided into many small classes. For example, the Love Flowers, usually made up of beauty and lovesickness, theseare the best performance in the Louts HillLove Flowers. The Life Flowers mostly based on the land and children, they are closely related to life topics, such as today's Production Flowers and Planting Flowers. There are also someSinging Flowers which reflected the development of history. And the worship songs mainly divided into two themes: the pray to god and thank the god, such as the "eight immortals in the hole", "12 peonysets of deities" and so on. With the development of the society, the Flower gradually add the business, work, new ideas to its content.Because of the life is more comfortable the contents of god songs were fade out from people's life. It's worthy to be mentioned that although the subjects were limited in the normal people's working life, the singer's creative inspiration is not bound by the content. They combin with the local dialect and create new lyrics that associate closely with times. Compared with folk 
songs of other nations and reigns, the subject of Louts Hill Flowers both have similarity and individuality, which is an entry point of the research on different kinds of folk songs.

\section{Regular Sets}

In Louts Hill Flowers, the 1st sentence usually has no actual meaning but set the rhyme, and it is called the "first tone". The first tone usually has the rhyme with every 3 sentences, each sentence has 7 words. The sentence set rhyme with 7 words usually ends with the words like "Le", "Me" and "Zhe", which requires the following sentences to stick to the rhythm. In addition to the first sentence, Lotus Flowers have sentences to call people's attention, which are often addedin the sentences except tail words. The last sentence of Lotus Flower is always the same chorus form, the words are "flower two leaves", this kind of models is the traditional inheritance of Louts Hill Flowers.

\section{The problems in Louts Hill Flowers's protection, inheritance and development}

Based on the principle of equality and mutual benefit, the government now is leading the cooperate actions among different reigns to protect the integrity of Flowers culture. The government should do their best to protect the intangible cultural heritage, improve their awareness on the protection, inheritance and development. To solve the practical difficulties, the government should keep a scientific attitude towards the collection, arrangement and innovation. As for the lack of funding, government should build a sound management mechanism.

In 2006, the Louts Hill "Flower Rally" was included in the first batch of national intangible cultural heritage list. After that Gansu province combined the Flowers development with the rural public construction and make a series of policies to adjust the leadership team to make a plan about the further development of culture. On March 9, 2009 the Artist Association of Louts Flowers was founded, republished the Louts Hill which kept science in the past 20years. The Artist Association of Louts Flowers have organized professionals to publish the Louts Hills and Louts Hills and Louts Flowers, Introduction of Louts Hills and Louts Flowers, You are the flower of Louts Hills, Travels in Louts Hills, Songs of Kangle, Songs of successor, and the Intangible heritageSounds of Nature. The government has accelerated the construction of hardware, and they build $17 \mathrm{~km}$ 's travel routine in Louts Hills with a series of cultural centers to make it easy for young people to learn the Flowers. For further mining and saving the unique Lotus Hills Flowers, the government will focus on highlighting the publicity platform "Chinese Flowers Protection Center", creating the Lotus HillsFlowers culture brand, launched the ecological tourism products of "Lotus Hill and Lotus Hill 'flowers'”.

But there have some urgent practical problemsneed to be solved by government departments. The first thing is to solve the regional disputes, protect and develop the original Flowers Rally, especially the Yehai Flower Rally and Zisong Mountain Flower Rally. These two Flower Rallies used to keep in harmonious, but in recent years they often occur some conflicts caused by the tourism economy. Because of these disputes, we can hardly see the singing festival today. The Flower Rally usually located in those places with beautiful scenery where in the national nature reserve. There come the conflicts: admission ticket of the national nature reserve with the money in people's pockets. This kind of conflicts blocked the development of Flowers cultures. Actually we can emulate what Hezheng county did in SongMing Rock Flowers Rally. They charged parking fee during the rally but local personnel do not need pay their tickets. Finally, training and payment of those successors have became the key problems to solve.Everyone knows the flowers singer is the 
backbone of the Flowers Rally. In today's situation, training the Flowers singers become an urgent project.

To inherit and develop the Flowers cultures better, the Flowers cultures should be combined with colleges through the music class. For a long time, the Flowers artists has always been the communicators and promoter of Flowers cultures. There never has such a school which can teach the Flowers as a course.So the best way is to hire representative of Flowers culture to give lectures in university, expanding the influence of Flowers culture.

The construction of Louts Hill Flowers Museum and the Folk Museum. We can startin the traditional museum and digital museum. The former has the basis of its existing collection that can collect and spread classic Flower melody and lyrics in the local teenagers. The latter has the basis of the digital data of non-material cultural heritage that canvisualize those data with its modern digital technology and network technology. Building shared links between the museum and Internet, they can help each other with their advantages.

\section{References}

[1] Xi Huimin. Northwest Flowers Theory [M]. Lanzhou university press, 1989

[2] Zhao Zongfu. The academic responsibility of protection and academic research [J]. Folk Cultural BBS, 2007 (03)

[3] Chao Gejin. Back to voice: oral poetics on the oral epic research as a starting point [J]. Journal of northwest ethnic groups research. 2014 (02)

[4] Wang Hongming, Ding Zuoshu. Lotus Hills and The Lotus Flowers [M]. Gansu people's press. , 2002

[5] KeYang. Lotus Hill Flowers Program Theory [J]. Journal of Guangxi institute for nationalities, 2002.11 